\title{
Expresiones de origen náutico en el nacimiento de las distintas formas de volar: aerostación, aviación y astronáutica*
}

\author{
Lorena M. A. de-Matteis **
}

\section{Resumen}

En la comunicación cotidiana se puede observar que el nivel léxico-semántico liga a la aerostación, la aviación y la astronáutica en una relación de continuidad de base analógica. Esta conexión se funda, en primer lugar, por procesos de trasvase terminológico de las respectivas técnicas y, luego, en la adopción social de las unidades léxicas de origen técnico, por el empleo de metáforas para explicar la nueva realidad. De esta manera, el análisis léxico muestra que aerostación, aviación y exploración espacial son concebidas socialmente y expresadas lingüísticamente con expresiones que remiten a la idea de navegación marítima.

Palabras clave: léxico, terminología, transportes, metáforas, español bonaerense

\section{Expressions of marine origin in the birth of the different ways to fly: aeronautics, aviation and astronautics}

\begin{abstract}
In everyday communication, a lexical-semantic connection of analogical base can be established between ballooning, aviation and astronautics. This connection is based, first, by a process of transference of the respective technical terminology, and then in the social adoption of the lexical units of technical origin, the similarities are reinforced by the use of metaphors to explain the new realities. Thus, the lexical analysis shows that ballooning, aviation and space exploration are socially conceived and linguistically denoted by expressions that refer to the idea of maritime navigation.
\end{abstract}

Keywords: vocabulary, terminology, transportation, metaphors, bonaerense Spanish

Recibido: 04-10-2011 Aceptado: 29-12-2011

* Proyecto Estilo(s) comunicativo(s) en la interacción verbal en español bonaerense: construcción de identidades, valores y creencias, dirigido por la Dra. Rigatuso y desarrollado en el Centro de Estudios Lingüísticos "Dra. M. B. Fontanella de Weinberg". Departamento de Humanidades. Universidad Nacional del Sur. Subsidio de Proyectos de Grupo de Investigación de la Secretaría General de Ciencia y Tecnología de la Universidad Nacional del Sur (P.G.I. 24/I191).

* Dra. en Letras, Universidad Nacional del Sur - CONICET, Argentina, lmatteis@uns.edu.ar 
Expresiones de origen náutico en el nacimiento de las distintas formas de volar: aerostación, aviación y astronáutica / Lorena de-Matteis

\section{Antecedentes ${ }^{1}$}

La historia de las voces para designar las realidades que la ciencia y la tecnología introducen en la vida social, tiene un atractivo especial para los historiadores de la lengua, pues permite apreciar cómo las palabras establecen entre sí nuevas relaciones de sentido que reestructuran sectores completos del léxico de una variedad lingüística. Las unidades léxicas, empleadas como términos en la ciencia y la técnica, pueden ser adoptadas por el lenguaje cotidiano de una comunidad (proceso de generalización o banalización), donde serán usadas, a veces, como términos, y otras como palabras (Cabré 1999). ${ }^{2}$ De cualquier manera, en muchos casos, sólo por su carácter de neologismos - una de las maneras de ver la diacronía de las lenguas en el nivel léxico (Lüdtke 1974)-, estas palabras pueden dar cuenta de procesos de cambio cultural y también de la conformación de nuevos imaginarios sociales.

A diferencia de lo que ocurre en otras lenguas, la historia del léxico aeronáutico y astronáutico en español no está muy estudiada. ${ }^{3}$ Existen antecedentes en los trabajos de V. Vivanco Cervero (2003, 2006) que recogen algunas observaciones sobre la terminología aeronáutica, aunque sin focalizar en los usos generalizados en la comunidad no especializada. ${ }^{4}$ En cambio, en este trabajo, nos ocuparemos de ciertos términos de la aeronáutica y de la astronáutica que han pasado a conformar el léxico cotidiano del español bonaerense -y de otras variedades del español

1 Una versión preliminar y la sección sobre metáforas náuticas en la aeronáutica de principios del siglo XX en la región bonaerense fue presentada en el Primer Congreso Internacional de Sociolingüística y Lingüística Histórica (Universidad Nacional del Sur, Bahía Blanca, noviembre de 2007) y se realizó en el marco del proyecto "Interacción verbal en español bonaerense: construcción de identidades, valores y creencias". (SGCyT-UNS 24 I152, dirigido por la Dra. E. M. Rigatuso). La sección referida a los principios del vuelo espacial reelabora materiales analizados para el II Concurso de Monografías Inéditas de Historia Aeronáutica y Espacial año 2009 (de- Matteis 2010a).

2 De manera sintética, la teoría comunicativa de la terminología establece que las condiciones de uso -contextos, fines comunicativos, hablantes, etc.-, serán las que determinen si una unidad léxica se emplea como término o como palabra (Cabré 1999: 124-125).

3 Álvarez de Miranda (2008: 1043) observa que "Por lo que a España y a la lengua española se refiere, el conocimiento de la evolución del léxico en relación con la historia social y la historia de las ideas presenta todavía importantes lagunas". Y, citando a Lapesa, coincide en que los principales cambios en la lengua española entre 1898 y 1936 ocurrieron en el vocabulario, tal como lo reflejan las sucesivas ediciones del DRAE de 1899, 1914, 1925 y 1936. En estas lagunas puede incluirse el vocabulario de la aviación.

4 Entre otros aspectos, Vivanco Cervero explora, en sus trabajos, el papel de mecanismos de designación cercanos a la metáfora en el campo aeronáutico, por ejemplo la eponimia y la deonomástica (2003). Esto muestra que la metáfora, o, de manera más amplia, la analogía no es un elemento ajeno en la conformación de vocabularios o terminologías técnicas.

(1)


también-, así como de expresiones asociadas que remiten por analogía a la tradición de la navegación marítima. Esto incluye unidades léxicas de la náutica que son calificadas por algún adjetivo que las restringe a los nuevos campos de uso; otras que son prefijadas evidenciando un proceso de comparación que tuvo lugar, primero, en las terminologías, y también expresiones metafóricas.

Desde una perspectiva diacrónica, a fines del siglo XIX y principios del siglo XX, para la aviación, y a mitad de siglo en relación con el vuelo espacial, las expresiones analógicas son recursos frecuentes en la prensa en español bonaerense como mecanismos lingüísticos que satisfacen la necesidad de los hablantes de explicarse la realidad del vuelo humano y que lo logran, en gran medida por remisión, al ámbito conocido de la navegación marítima.

Nuestro objetivo, entonces, será dar cuenta del funcionamiento que la analogía tiene en la conformación del vocabulario cotidiano, referido a las distintas modalidades del vuelo humano en la comunidad lingüística del español bonaerense, entendiendo, además, que estas expresiones definen una continuidad de ideas centrales en el imaginario social sobre el vuelo atmosférico y, luego, sobre el vuelo espacial, todas posibilidades que son entendidas por referencia a la náutica. Para ello, partimos de la premisa de que la navegación marítima posee una de las tradiciones de más larga historia en el ámbito del transporte, lo que le otorgó a su vocabulario gran poder explicativo o aclaratorio para aprehender las nuevas realidades. En particular, la navegación por mar estaba muy presente en la vida de la sociedad de la época del Centenario, pues buques a vapor y transatlánticos eran el principal medio de locomoción para comunicar a países de los distintos continentes. Luego, desde mitad del siglo XX, si bien se sigue manteniendo como modalidad del transporte de personas, el campo náutico influye en el vocabulario del vuelo espacial, porque se continúa en una especie de relación transitiva a través de su éxito en el campo de la aeronáutica, que permite trasladar al de la astronáutica algunos elementos que habían tenido origen en la navegación marítima (y otros ya propios de la aviación, que no consideraremos por escapar al objeto del presente trabajo).

\subsection{Marco teórico y metodológico}

La perspectiva asumida en el análisis integra aportes de sociolingüística y análisis histórico del discurso (Conde Silvestre 2007, Schiffrin y otros 2001, Wodak y Meyer 2001). Además, se apela a estudios sobre 
Expresiones de origen náutico en el nacimiento de las distintas formas de volar: aerostación, aviación y astronáutica / Lorena de-Matteis

metáforas (Lakoff y Johnson 1998, Barei y Pérez 2006) y terminología científica y técnica (Cabré 1999, Martín Camacho 2004, Vivanco Cervero 2003), entre otros.

Para el caso de las modalidades de vuelo atmosférico (aerostación y aviación), el corpus analizado está conformado por escritos correspondientes a diversos tipos textuales, publicados por la revista Caras y Caretas (CyC), entre 1898 -año de aparición del primer número- y abril de 1914, año en el que se inicia la Primera Guerra Mundial y la aviación encuentra su primera aplicación práctica. Por otra parte, en el caso del vuelo espacial, tomamos una serie de artículos del diario La Nación publicados entre los años 1957-1969, fechas que definen -por el significado histórico y el ritmo acelerado de las experiencias- una "edad de oro" y están marcados, además, por la "carrera espacial" que caracteriza a esta etapa de la "Guerra Fría" entre Estados Unidos y la ex Unión Soviética.

En ambos casos, la selección de textos de prensa escrita para identificar las expresiones circulantes en la sociedad se justifica a partir de la consideración de que los medios "forman e informan, en un movimiento de vaivén, el imaginario de una época y los modos en que se desarrolla la cotidianeidad" y porque el periodista, en estos textos, "escoge las metáforas del "contexto de la vida", sometiéndolas a una valoración activa dentro de su propio enunciado" (Mottura 2006: 38-40). Por otra parte, su aparición repetida es una de las marcas de la cotidianeidad de los discursos, y todas las expresiones registradas aparecen en diversos textos, la mayoría de ellas en más de una ocasión.

\subsection{Analogía: banalización de términos de trasvase y metáforas}

\subsubsection{La analogía en la conformación de términos}

Si consideramos, en primer lugar, los orígenes de las voces técnicas de la aeronáutica, podemos mencionar el trabajo ya clásico de L. Guilbert en torno al origen del vocabulario francés de la aviación. El autor observa que en su conformación influyó un vocabulario científico que antecedió a la práctica técnica de la aviación y que había tomado términos de disciplinas relacionadas como la física, la ornitología, y la aerostación, pero también de otra disciplina afín, la navegación marítima (Guilbert 1965: 68-69). 
Este proceso de transferencia, también llamado de trasvase, se funda en un procedimiento analógico: en este caso, se detectan similitudes entre ambas modalidades del transporte, que justifican la adopción de algunas de las voces de la náutica para su empleo en la aerostación y en la aviación. En definitiva, el trasvase es similar al proceso de terminologización por el que una voz del léxico general ve precisado su significado, en el marco de una disciplina dada. En ambos casos, opera un proceso analógico, sólo que en el trasvase ocurre a partir de una unidad que ya era un término (Martín Camacho 2004: 52-53).

En el caso del español, que adoptó muchas de las voces del francés como préstamos técnicos, podemos ver que en la generalización en los usos cotidianos de la comunidad, estas unidades léxicas trasladan al dominio público las analogías que las sustentan. Es decir, la banalización de estos términos no supone la anulación de las analogías que les dieron origen, sino que, sobre su base, surge un conjunto de otras expresiones que las complementan, remitiendo todas ellas a un orden metafórico (Barei y Pérez 2006).

\subsubsection{Las metáforas}

En tanto figura retórica, la metáfora se considera un tropo, pues reemplaza un elemento determinado del discurso por otro proveniente de un ámbito diferente, o, como señala Rothbart (1984: 596), por un proceso mediante el que uno de los sujetos implicados - el secundario, expresado en la metáfora- transfiere rasgos semánticos al otro -el primario, o del que se está hablando en realidad-. Es central, para esta noción, el hecho de que "basta omitir la analogía expresa de la comparación, aquella que mantiene la distinción de los campos, para que hayamos pasado a lo metafórico" (Barei 2006: 11).

Ahora bien, si el sistema conceptual de una comunidad es en gran medida figurado, como han puesto de manifiesto los estudios sobre el empleo de expresiones metafóricas en el habla cotidiana (Lakoff y Johnson 1998 [1980], Sanmartín Sáez [2000], Barei y Pérez [2006], entre otros) y las metáforas organizan en forma coherente un grupo de conceptos a través de un vínculo analógico con objetos de otro orden, podemos afirmar que la contribución que hacen las metáforas náuticas y otras expresiones fundadas en procesos de analogía semántica a la formación de los imaginarios sobre las distintas modalidades del vuelo tiene su explicación en la historia de las distintas modalidades de transporte y las ciencias que las hacen posibles. Como hemos señalado, a 
Expresiones de origen náutico en el nacimiento de las distintas formas de volar: aerostación, aviación y astronáutica / Lorena de-Matteis

finales del siglo XIX y principios del XX existía un vocabulario técnico para la locomoción aérea. Pero este vocabulario era dominado sólo por investigadores e inventores, profesionales o amateurs. La sociedad en su conjunto, en cambio, no tenía razones para conocer este vocabulario, y menos aún en una región como la nuestra: en la Argentina de principios del siglo XX, no se realizaron avances revolucionarios en el campo de la experimentación aeronáutica, sino que, con algunos años de diferencia, con Francia y otros pocos países, los pioneros del vuelo local 5 importaron los avances alcanzados y los demostraron al público nacional. Lo mismo puede sostenerse, más adelante, sobre el vuelo espacial, ya que, en general, los países hispanoparlantes no realizaron ni realizan actividades de vuelo espacial tripulado de manera autónoma.

Entonces, si el sistema conceptual de una comunidad es en gran medida metafórico, y si aceptamos que para que las propiedades y relaciones de un dominio conceptual se proyecten en otros, este dominio debe tener una presencia importante en la experiencia cotidiana y habitual de una comunidad (Alarcón 2004: 46), las metáforas de origen náutico son una de las posibilidades más lógicas o naturales para explicar las realidades del vuelo humano en los períodos históricos considerados. Los siglos de navegación marítima ofrecen a los hablantes un orden conocido de acciones, personas y objetos, así como de riesgos e imágenes que les permiten comprender al nuevo orden de la locomoción aérea. Así, tomadas en su conjunto, las expresiones de origen náutico analizadas en este trabajo cumplen una función cognitiva importante ${ }^{6}$, pues contribuyen a conformar los imaginarios sociales sobre la aerostación, la aviación y la exploración espacial, entendiendo por imaginario una representación colectiva, es decir, una idea o imagen sobre la sociedad y todo lo que tiene que ver con ella (Baczko 1991:8).

\subsection{Organización conceptual de las expresiones de origen náutico}

Para poder sostener que hay una concepción metafórica de la acción de volar como una forma de navegación, las expresiones que vinculan ambos dominios, el náutico y el aéreo -y luego también el espacial-, deben poder ordenarse consistentemente. Y los datos muestran que

5 Nos referimos al Ingeniero Jorge Newbery, su hermano Eduardo Newbery, el Ingeniero Mascías y algunos extranjeros como el italiano Bartolomeo Cattáneo y el francés Henri Brègi, entre otros.

6 Sobre el valor cognoscitivo de las expresiones metafóricas, cfr. Barceló (1980). 
esta organización se constata de manera efectiva, ya que las expresiones registradas se relacionan entre sí de manera estrecha y se organizan en torno a una metáfora de base que podemos enunciar, primero, como "el aire es un océano" y, más adelante, como "el espacio es un océano (cósmico)". De esta analogía básica, se desprende un conjunto de ideas asociadas que pueden sintetizarse de la siguiente manera:

a) El aire/la atmósfera/el espacio es un océano.

b) Volar en el aire/espacio son formas de navegar.

c) Los vehículos para transportarse en el aire/espacio son naves y buques y tienen semejanza estructural con estos.

d) Los vehículos aéreos/espaciales maniobran como los buques.

c) Quienes tripulan los vehículos aéreos/espaciales son nuevos tipos de navegantes.

\section{Expresiones de la náutica en el léxico de la aerostación y la aviación (1898-1914)}

De acuerdo con las analogías enumeradas en la sección precedente, las voces y expresiones que remiten al ámbito náutico pueden analizarse de la siguiente manera:

a. El aire como un océano es presentado en un conjunto amplio de metáforas que expresan la similitud entre el medio acuático y el atmosférico. La más transparente de estas expresiones es mar aéreo que, junto con mar de nubes, aparece con bastante frecuencia:

(1)A una altura de 200 metros, la hélice ascensional se detuvo y obró independientemente el propulsor de atrás; el globo deslizóse por el mar aéreo ("La trágica muerte del aeronauta Barón de Bradsky", CyC No215, 15/11/1902). ${ }^{7}$

(2)A las ocho de la mañana, finalmente, había un cielo claro sobre el globo, que avanzaba á una altura de 1.500 metros sobre el inmenso mar de nubes, del que surgían como islas los picos de las montañas de una altura de 1.200 ("El viaje en globo del archiduque Leopoldo", CyC N²02, 16/8/1902).

7 En todos los ejemplos citados, se respetarán las convenciones ortográficas de los textos originales y los destacados en itálicas nos pertenecen. Si hay itálicas en el original, empleamos negritas para distinguirlas. 
Expresiones de origen náutico en el nacimiento de las distintas formas de volar: aerostación, aviación y astronáutica / Lorena de-Matteis

En ocasiones, en lugar de la imagen del mar aparece la del océano, como en el siguiente texto, en el que Jorge Newbery destaca las virtudes de los globos esféricos:

(3)Y así, flotando sobre el océano inconmensurable de nubes, los sentimientos nobles y generosos, muchas veces reprimidos en el fondo de nuestro ser, se levantan sobre las necesidades mezquinas de la vida terrestre (Jorge Newbery, "La conquista del espacio", CyC $\left.\mathrm{N}^{0} 737,16 / 11 / 1912\right)$.

Por otro lado, el riesgo de la navegación marítima se da también en el océano aéreo, que es considerado como un posible piélago ${ }^{8}$ al anticipar en el siguiente texto el peligro de que un proyecto de aeroplano -al que se designa con la voz aviador-se desplome:

(4)Si al "aviador Miniussi" no le falta ningún tornillo que lo eche á pique en el piélago inmenso del vacío, no estamos distantes de ser los hombres más pájaros de la América del Sud (...) ("Una máquina voladora", CyC No 495, 28/3/1908).

Si el aire es un océano, presenta a sus nuevos "marinos" riesgos y desafíos similares a los que el mar presenta a los navegantes, como las "corrientes" del viento:"

(5) (...) como sucede con todos los demás aparatos más ó menos perfeccionados que se han inventado hasta ahora con el propósito de hacer práctica la navegación; lejos de necesitarla, combate la corriente del viento, pues avanza contra ella ("El buque aéreo de Santos Dumont", CyC N¹07 19/10/1900).

b. De acuerdo con la concepción del aire como un océano a conquistar, cada vez que se eleven, los vehículos aéreos y las personas que los conduzcan estarán "navegando". La metáfora del vuelo como "navegación" está en la base misma del sintagma navegación aérea que registramos con una elevada frecuencia. La presencia del adjetivo evidencia que hay un proceso de comparación y que la voz navegación, nombre de una ciencia, y el verbo navegar, comienzan a experimentar

8 Recordemos que una de las acepciones de la voz piélago, según el DRAE, es la 'parte del mar que dista mucho de la tierra'.

9 Aunque no forma parte del corpus analizado en este trabajo, es interesante mencionar un tratado de aviación con prólogo del año 1918 titulado La aviación al día, de Charles C. Turner y traducido al español por José Ma. Borrás y que fue publicado en Barcelona. El texto es interesante para marcar coincidencias entre distintas variedades del español y, sobre todo, para destacar una concepción típica de la época en torno al espacio aéreo, pues el capítulo dedicado a la caracterización meteorológica del espacio aéreo se titula "El océano aéreo".

1282


un proceso de ampliación semántica, como se ve en los siguientes ejemplos: ${ }^{10}$

(6) Aunque hace ya muchos años que el problema de la navegación aérea atormenta la imaginación de los inventores, se puede decir con acierto que sólo en el último lustro del siglo XIX se ha avanzado de manera apreciable hacia la solución del problema (...) ("Los mejores globos dirigibles inventados en 1900", CyC N¹25, 23/2/1901).

(7)El ensayo más notable de esta máquina de navegar en el espacio se efectuó el 17 de octubre último ("Los mejores globos dirigibles inventados en 1900”, CyC N¹25, 23/2/1901).

Durante todo el período, estas expresiones se emplean con mayor frecuencia para globos y dirigibles, y así, en 1910, se sugiere la explotación comercial de estos vehículos en "compañías de navegación aérea":

(8) Según lo indicamos en nuestro número anterior, este nuevo dirigible, construído con un objeto de explotación comercial por cuenta de la compañía de navegación aérea de Berlín, medía 148 metros de largo, cubicando 19.000 metros ("El "Zeppelin VII" ó "Deutschland", CyC No 617, 30/7/1910).

c. De manera coherente con las expresiones precedentes, para navegar este nuevo océano, los tripulantes necesitan de vehículos apropiados, es decir, de naves, o más bien aeronaves, que, sobre todo al principio de este período, se asimilan a buques o barcos. Así, entre las expresiones que encontramos, se cuentan buque aéreo y barco déreo, que se aplican, sobre todo, a globos y dirigibles con los que tienen una semejanza formal:

(9)El globo dirigible del señor Santos Dumont ha hecho, efectivamente, cinco excursiones de París a los alrededores de la ciudad (...) Este globo o "buque aéreo" como le llama su inventor, no necesita la ayuda del aire para navegar (...) ("El buque aéreo de Santos Dumont”, CyC N¹07, 19/10/1900).

Resulta interesante la función de las comillas que explicitan el orden metafórico al que se apela en el texto, mostrando de manera clara al lector

10 La voz navegación continúa ampliando su significado. En la actualidad, también se pueden navegar espacios virtuales como el de internet, o se puede navegar en una ciudad empleando un sistema como los GPS (del inglés global positioning system, 'sistema de posicionamiento global' para automóviles. 
Expresiones de origen náutico en el nacimiento de las distintas formas de volar: aerostación, aviación y astronáutica / Lorena de-Matteis

la función ilustrativa de la expresión que pretende hacer comprender una idea nueva mediante otra conocida. Pero, además de estas voces, también se registra el empleo del término aeronave: ${ }^{11}$

(10) Los inventores de esta aeronave son un francés, M. Auguste Baudron, y un inglés, Mr. Cecil Barth (...) ("Ensayo de una nueva aeronave en el Palacio de Cristal de Londres", CyC Nº136, 11/5/1901).

En este caso, la voz presenta las raíces griegas cultas típicas en la formación de términos, pero, en otras oportunidades, aparecen también las designaciones nave o navío, sin el prefijo \{aero-\} y sin que las acompañe tampoco el adjetivo aéreo:

(11) La nave, á fatal deshora combinada por los hombres que alas quieren tener, ha sido fabricada en París por la casa Godard (...) ("Expedición al polo norte", CyC Nº409, 4/8/1906).

(12) (...) El «Patrie» se comportó durante toda la travesía con la seguridad de un navío admirablemente equilibrado y gobernado (...) ("El último viaje del "Patrie"', CyC Nº482, 28/12/1907).

En los siguientes ejemplos, vemos que los diseños cada vez más avanzados y la sensación de la guerra que se aproximaba, permiten que estos vehículos menos pesados que el aire se presenten como tipos especiales de buques, destructores, cruceros o acorazados:

(13) Según noticias recientemente recibidas, Mr. Yamada, (...) ha obtenido patentes por varios perfeccionamientos para los buques aéreos (...) El mismo inventor ha estudiado la aplicación de los voladores para el ejército, y no sólo ha ideado un buque aéreo, seguro y manejable, sino que además ha trazado los planes de un destroyer aéreo ("El aeroplano japonés", CyC No 576, 16/10/1909).

(14) El crucero aéreo "Géneva" ("Los buques de guerra aéreos", CyC No 633, 19/11/1910, [descripción de grabado]).

(15) Dos acorazados de los aires se encontrarán en singular combate, cambiando tiros de melinita ("La guerra en los aires", CyC No733, 19/10/1912, [descripción de grabado]).

11 Es interesante observar que, como en el caso del sintagma navegación aérea, también la voz aeronave se continúa empleando en la actualidad como designación general para todo tipo de vehículo aéreo. Fue incorporada al DRAE en 1925, pero hasta 1956 su acepción se restringía al ámbito de la aerostación, a pesar de que se constataban ejemplos de aplicación a vehículos más pesados que el aire. Recién en 1970 se incorpora la definición más general de 'vehículo capaz de navegar por el aire'. 
Si los vehículos destinados a surcar los cielos en lugar de las aguas son concebidos como barcos, es comprensible que muchos de sus componentes estructurales se piensen como semejantes a los de los buques de la época. Así, los términos náuticos que designan las distintas partes de un buque (hélice, timón, popa, quilla, puente, etc.) pasan a conformar el vocabulario aeronáutico de la época como se ve en las siguientes frases aisladas de su contexto: ${ }^{12}$

(16) "una hélice de dos hojas, bate el aire como la hélice de un vapor" ("El buque aéreo de Santos Dumont", CyC N¹07 19/10/1900).

- "el timón se dirige por medio de una rueda que está en el puente" ("La aeronave del Dr. Barton", CyC N¹90 24/5/1902).

- "respondiendo prontamente al gobernalle"13 ("Ensayo de una nueva aeronave en el Palacio de Cristal de Londres", CyC N¹36, 11/5/1901, itálicas en el original).

- "la quilla del "Santos Dumont N5" ("Los experimentos de Santos Dumont con su aeronave", CyC N¹50, 17/8/1901, descripción de fotografía).

- "se levantó la popa" ("Globo malogrado", CyC N³60, 26/8/1905).

En todos estos casos, resultan interesantes las aclaraciones "como la hélice de un vapor", donde se hace explícito el proceso de analogía, y el destacado en el original de la voz gobernalle, que opera como si la palabra estuviera entrecomillada y alerta al lector, no sólo sobre el préstamo del francés, sino sobre el uso metafórico del término náutico para designar a la estructura equivalente en la aeronave. Estos recursos contribuyen a ofrecer claridad conceptual a los textos y reflejan las estrategias de producción de sus autores, interesados en difundir las actividades aéreas a un público masivo.

d. Las maniobras de algunos de estos vehículos aéreos, en especial de los globos y dirigibles, se presentan como las de los buques. De esta forma, se registran diversas expresiones como las siguientes:

(17) Cortar amarras: Una enorme muchedumbre presenció la partida del globo "Portugal", que al cortarse las amarras que lo ligaban a tierra, fue saludado con ruidosos aplausos (...) ("Ascensión en globo", CyC No355, 22/7/1905).

12 Algunas de estas voces continúan empleándose en la actualidad en relación con los actuales aviones, pero otras, como quilla, no. Resta en la continuidad de nuestro trabajo, determinar si su empleo subsiste en los vehículos menos pesados que el aire.

13 Gobernalle, según el DRAE, designa también 'el timón de la nave’. 
Expresiones de origen náutico en el nacimiento de las distintas formas de volar: aerostación, aviación y astronáutica / Lorena de-Matteis

(18) Ser botado al aire: Una gigantesca aeronave, un nuevo dirigible construido por los señores Vickers, acaba de ser "botado al aire" en Barrow, Inglaterra ("Un nuevo dirigible", CyC Nº70, 5/8/1911).

(19) Ganar el puerto de amarre: Salido de su galpón de Sartrouville, el navío aéreo, piloteado por los señores Kapferer y Surcouf, llegaba al campo de las carreras casi al final de la reunión y (...) volvía á ganar, sin tropiezo alguno, su puerto de amarre ("El primer dirigible destinado á un servicio público", CyC No 565, 31/7/1909).

(20) Atracar en un muelle: Un navío aéreo atracado á un muelle también aéreo ("Los buques de guerra aéreos", descripción de fotografía, CyC No 633, 19/11/1910).

(21) Poner en franquía: ${ }^{14}$ Llegado el momento oportuno, (...) el globo fue puesto en franquía y lanzado al espacio ("De Italia. El nuevo dirigible militar", CyC No 574, 2/10/1909).

(22) Poner la proa en dirección a: Volvió á partir de esa ciudad á las 8 y media del día siguiente, poniendo la proa en dirección á Dortmund (...) ("El "Zeppelin VII" o "Deutschland", CyC No 617, 30/7/1910).

Aunque menos frecuentes, estas expresiones náuticas pueden aplicarse también a los aeroplanos. Así, en 1909, en una nota dedicada a una posible invasión aérea a Inglaterra por parte de Alemania, aparece también el verbo zarpar, aunque lo que harían sería 'despegar':

(23) Estos aeroplanos zarparían del puerto de Calais y en menos de media hora podrían desembarcar en el territorio inglés del condado de Kent un ejército de cien mil hombres bien equipados y armados ("Una invasión aérea", CyC No 538, 23/1/1909).

Como hemos anticipado, también las expresiones que relacionan la forma de maniobrar de las aeronaves con la de los buques parecen restringirse más bien a los globos y dirigibles. Es probable que los procesos analógicos que subyacen resultaran más aceptables a los hablantes para este tipo de vehículos y no para los aeroplanos, cuya forma de maniobrar era, en gran medida, diferente -mucho más versátil- por ser más pesados que el aire y contar con un sistema de sustentación por planos, más similar al de las aves que al de los globos, factores que tor-

14 Poner en franquía es una expresión náutica para indicar la 'situación en la cual un buque tiene paso franco para hacerse a la mar o tomar determinado rumbo' (DRAE).

186


naban más difícil establecer la semejanza. De hecho, los datos parecen indicar que las metáforas y comparaciones explícitas, en el caso de los aeroplanos, tienen su origen más en el ámbito de la ornitología que en el de la náutica.

e. Las designaciones de navegante aéreo o aeronauta ${ }^{15}$ dan cuenta de la última idea que contribuye a configurar conceptualmente este período inicial del imaginario social sobre la aviación. Los sujetos que realizan las acciones de volar son semejantes a los marinos, son "navegantes", como manifiesta este texto de 1901 que relata con humor los avances incompletos de la técnica de los hombres:

(24) (...) Pero ya que no puede ser la navegación submarina, dijeron los sabios:

- La cuestión es navegar por los aires; vamos pues a la navegación aérea.

Y patapún!! Salen, aparecen, brotan, aquí, allá y acullá, y aún mucho más allá... seis o siete navegantes aéreos. Y uno de ellos se lanza a atravesar el mar, con su globo dirigible a voluntad del navegante, claro (Angel María Segovia, "Si no fuera por...", CyC No166 7/12/1901, los destacados en negrita nos pertenecen, itálicas en el original).

En este ejemplo, el último empleo navegante no apela a ninguna forma de adjetivación ni de modificación morfológica, pero, como ya dijimos, la expresión más frecuente que designa a las personas que vuelan es la que se forma mediante el prefijo \{aero-\} y la raíz \{nauta\}, aeronauta. Este término se difunde e inserta en los usos cotidianos y lo encontramos en frases referidas a la estructura que las personas ocupan en globos y dirigibles, como, por ejemplo, en estas dos breves expresiones:

(25) "la plataforma queda reservada para el aeronauta" ("Ensayo de una nueva aeronave en el Palacio de Cristal de Londres", CyC $\mathrm{N}^{\circ} 136,5 / 11 / 1901$ ).

- "el lugar destinado para los aeronautas" ("La aeronave del Dr. Barton", CyC N¹90, 24/5/1902).

15 En la actualidad, se ha generalizado la voz aeronavegante. Así aparece en el presente en algunos de los nombres de los gremios del sector aeronáutico argentino: "Asociación Argentina de Aeronavegantes". 
Expresiones de origen náutico en el nacimiento de las distintas formas de volar: aerostación, aviación y astronáutica / Lorena de-Matteis

Es interesante que esta designación se emplee no sólo para los pilotos de globos y dirigibles, sino también para los de aeroplanos, tal como ocurre en este texto:

(26) El aeronauta francés M. Bonnier, llegando a Jerusalén en su monoplano. Su aparición causó gran impresión entre los indígenas ("Notas varias", CyC No 802, 14/2/1914).

Este uso es el único registrado en el corpus hasta el momento. Consideramos que se trata de un caso excepcional, pues para los tripulantes del vuelo en aeroplano se prefieren las voces aviador, volador o piloto aéreo, entre las que sólo piloto tiene un origen náutico (de-Matteis 2007). ${ }^{16}$ En otras palabras, este ejemplo muestra el uso de la voz aeronauta ya no cómo un término de significado preciso, unívoco, sino con una amplitud semántica que evidencia su empleo en tanto palabra en los usos no especializados de la comunidad.

\section{Expresiones de la náutica en el vuelo espacial (1957-1969)}

El segundo período que consideraremos en este trabajo comprende los primeros doce años de experiencia astronáutica, y está definido por el inicio de la actividad espacial soviética con el lanzamiento del Sputnik (1957) y por la llegada del hombre a la Luna (1969), logro máximo de la astronáutica estadounidense del momento. Aunque ya está instalado en la sociedad un imaginario respecto del vuelo humano, con la astronáutica se incorporó un nuevo entorno físico para la posibilidad del mismo y esto conlleva un necesario número de adaptaciones y neologismos. Así, en los comienzos de la actividad espacial, la sociedad se encontraba en una situación que, en muchos sentidos, se asemejaba a la de principios de siglo, puesto que se comenzó a incorporar un léxico específico para referirse a las nuevas actividades que llevaban a cabo las dos potencias mundiales. ${ }^{17}$

En el marco de la carrera espacial que se estableció entre Estados Unidos y la Unión Soviética y que caracteriza la totalidad del período

16 Proviene del antiguo italiano pedotto o pedotta, a su vez del griego * pēdōtēs 'timonel', derivado de pēdón 'timón'Luego fue tomado también por el francés medieval como pillot.

17 El aprovechamiento de las nuevas realidades, como referente de potencial persuasivo en el género publicitario en ambos períodos, da cuenta de la similar percepción social de asombro ante los nuevos fenómenos o modalidades de transporte. 
que analizamos (1957-1969), entonces, se produce la adopción de parte del vocabulario de la aviación para esta nueva disciplina, y esto incluye algunas de las expresiones que la aviación tomó de la navegación marítima: navegar, astronave, astronauta, entre otras que analizaremos a continuación siguiendo el mismo esquema de relaciones de analogía establecido en la sección 1.3.

a. Si bien nuestro análisis en esta sección se centra en el período 1957 1969, resulta interesante hacer alusión a algunos ejemplos correspondientes a años anteriores. Cuando comenzamos a buscar usos tempranos de la terminología astronáutica en medios periodísticos bonaerenses, detectamos una nota aparecida en Caras y Caretas en el año 1928. La nota en cuestión, firmada por Gabrielle Camille Flammarion y traducida por C. E. M. (sin más detalles en el texto), introduce algunas de las voces que veremos más adelante y presenta la idea de una "navegación sideral":

(27) Otros eruditos, espíritus curiosos y avisados, han tratado este cautivante problema de la navegación sideral (G. C. Flammarion, "La posibilidad científica de las visitas interplanetarias", CyC $\left.\mathrm{N}^{\circ} 1554,14 / 7 / 1928\right)$.

El ejemplo es, en lo conceptual, similar a los analizados en la sección precedente. La analogía con el mar, en este caso, se traslada de la atmósfera al espacio exterior y se presenta la "navegación sideral", como antes a la aeronáutica, como uno de los "problemas" para la ciencia moderna. Ahora bien, pese a este temprano ejemplo que ya evidencia una continuidad en la idea de navegar en los distintos medios físicos -agua, aire y espacio-, el espacio no es presentado en nuestro actual corpus correspondiente al período 1957-1969 como una forma de mar. Es decir, no encontramos expresiones metafóricas del tipo *océano cósmico/sideral o * mar espacial ${ }^{18}$, sino que los textos hablan de espacio y del vuelo espacial. Es probable que la analogía no haya podido mantenerse, debido a que el espacio no es un fluido como el agua o el aire. Sin embargo, pese a que no detectamos esta noción metafórica, muchas de las restantes ideas asociadas con la navegación sí se mantienen.

b. El texto de 1928 al que hacíamos referencia es interesante también, porque en él aparece la voz de origen técnico astronáutica, en el que

18 Esto no significa que luego estas expresiones no aparezcan, o que no aparezcan en otros registros. Las traducciones del reconocido divulgador científico Carl Sagan, por ejemplo, introducen reiteradamente la expresión océano cósmico. 
Expresiones de origen náutico en el nacimiento de las distintas formas de volar: aerostación, aviación y astronáutica / Lorena de-Matteis

se destaca el prefijo \{astro-\} y se reitera así la idea de navegar por el espacio:

(28) Para encarecer estos interesantes experimentos y el desarrollo de la "Astronáutica" -nombre cuya paternidad la debemos al novelista Rosny, ainé, [sic]- esta joven ciencia que tiene por objeto la conquista de la alta atmósfera y luego la del cielo de Urania, M. Roberto Esnault Pelterie y un generoso amigo del progreso, M. Andrés Hirch, (...) han fundado un premio anual de cinco mil francos para los años 1928, 1929 y 1930. (...) (G. C. Flammarion, "La posibilidad científica de las visitas interplanetarias", CyC No1554, 14/7/1928).

Ahora bien, ya en el período que nos ocupa, esta palabra es empleada en la prensa escrita desde el principio efectivo de la exploración espacial. Así, con motivo del lanzamiento del Sputnik ruso, el diario La Nación publica una nota dedicada a esta actividad en Argentina:

\section{(29) En el Instituto de Experimentaciones Astronáuticas}

La entidad del título, que realiza una exposición sobre temas astronáuticos en la calle Florida 640 y se propone llevar a la práctica la construcción de cohetes interplanetarios, dio a conocer una declaración, en la que expresa que el 4 de octubre de 1957 es "uno de los más felices para los astronautas de todo el mundo" ("En el Instituto de Experimentaciones Astronáuticas", LN, 6/10/1957, p.8).

Aquí puede verse que la palabra astronáutica -empleada en el ejemplo como adjetivo- no era, entonces, extraña en las publicaciones periodísticas de los grandes medios aunque todavía se encontraba en su período neológico. ${ }^{19}$

Por su parte, en todo el período se registra la idea de navegar por el espacio:

19 El momento en que un diccionario incorpora voces al conjunto de lemas, constituye un indicador aproximado del momento en el que finaliza el período neológico. Para ello recurrimos al DRAE, porque se trata de un diccionario no terminológico y, como tal, permite ver las voces que de manera efectiva se incorporan al uso habitual de la comunidad. En tal sentido, hemos constatado algunas coincidencias interesantes respecto de los períodos neológicos del conjunto de las voces y de la periodización adoptada en este trabajo. Así, muchas voces de la aerostación y la aviación fueron incorporadas en el DRAE de 1914, fecha en la que finaliza el período de gestación de estas actividades, mientras que otras del campo de la astronáutica se incluyen a partir de 1970, en la que ya había finalizado la etapa fundacional de los programas espaciales. En el caso de la voz astronáutica, no aparece en los diccionarios académicos hasta 1970, cuando es incorporada al DRAE con la acepción de 'ciencia o arte de la navegación entre los astros'. 
(30) (...) Quedan atrás los pioneros, los precursores -sobre todo en el campo de la cohetería-, las pruebas con pequeños animales, algunos de los cuales inscribieron su nombre en la historia de la navegación a través del espacio exterior, como la perra Laika y el mono Bonny ("El hombre hacia la Luna", LN, 16/7/1969, $3^{a}$ sección dedicada al Apollo 11, p.1).

c. Para designar los distintos vehículos espaciales en el período que nos ocupa, encontramos ampliamente testimoniadas las voces de origen técnico astronave y cosmonave, formadas por prefijos y raíces de origen griego. También estos son nuevos términos formados por semejanza con otros preexistentes en otras disciplinas y que pasan al lenguaje cotidiano, trasladando sus relaciones de analogía con el mundo de la aeronáutica y la navegación marítima. Así, pese a sus diferencias técnicas, todas las cápsulas ${ }^{20}$ de los sucesivos programas norteamericanos son denominadas astronaves, mientras que las soviéticas reciben la designación de cosmonaves. ${ }^{21}$

(31) El hombre flota en el espacio, vinculado a la astronave por el cordón umbilical que tiene la doble función de suministrarle oxígeno y electricidad, amén de impedir que se pierda en la inmensidad sideral ("Cronología de la gran aventura", LN, 16/7/1969, $3^{a}$ sección dedicada al Apollo 11, p. 2, descripción de fotografía).

En ocasiones, puede aparecer también la variante cosmonavío y, si bien la selección de los prefijos tiene una marca político-ideológica, a veces se emplean las voces con el prefijo \{cosmo-\} para referirse también a los vehículos norteamericanos, como ocurre en el siguiente ejemplo correspondiente a final del período:

(32) Domingo 20: 13.52, transmisión de televisión en colores de las dos cosmonaves después de haberse separado; (...) 16.19, Aguila se posa en la superficie selenita, en un punto del Mar de la Tranquilidad, siendo el primer cosmonavío tripulado que llega a otro cuerpo celeste ("Cronología del vuelo de la nave espacial", LN, 16/7/1969, p. 2).

20 Cápsula es una voz alternativa para astronave o cosmonave, usada para distinguir la sección del cohete del espacio habitable y recuperable en cada programa espacial, tanto soviético como norteamericano.

21 Pese a la elevada frecuencia con la que se la registra, astronave no es recogida en el DRAE de 1970, sino en el Diccionario Manual de 1983, con la definición de 'vehículo espacial usado en la astronáutica'. Lo mismo ocurre con cosmonave que es definida como 'vehículo capaz de navegar más allá de la atmósfera terrestre'. 
Expresiones de origen náutico en el nacimiento de las distintas formas de volar: aerostación, aviación y astronáutica / Lorena de-Matteis

Además, se registran designaciones alternativas para los vehículos espaciales que también se vinculan con el orden metafórico de la navegación marítima. Algunas de ellas son los sintagmas nave del espacio y nave espacial; éste último es el que, en la actualidad, resulta uno de los más frecuentes en el discurso cotidiano de los hablantes.

(33) Hoy el Sr. W. N. Neat, de Gran Bretaña, técnico de la De Havilland Engine Co., se refirió al poder actual en las futuras naves del espacio ("El congreso de astronáutica se inaugurará hoy", LN, 8/10/1957, p. 1).

Mediante la abstracción de las diferencias (Barei 2006: 12), se mantiene la continuidad en la consideración de todos los vehículos que sirven para volar como formas especiales de naves, concepción destacada por la aparición ocasional de expresiones que parecen adaptadas de los textos de principios del siglo XX, como buque del espacio o navio sideral:

(34) (...) Al mismo tiempo, los cohetes que solamente partieran con toda su fuerza impedirían el descenso del buque del espacio cuando llegue a su destino ("El congreso de astronáutica se inaugurará hoy", LN, 8/10/1957, p. 1).

(35) Los rusos han hablado muy poco de lo que hizo su astronauta, y en lo relatado nada han revelado acerca de si intentó controlar su navío sideral ("Shepard descansa bajo control médico", LN, 7/5/1961, p. 1).

Contrariamente a lo que se podría pensar, navío sideral no es una alternativa que se limite a los primeros años de la exploración espacial, cuando su novedad requería de las expresiones analógicas y metafóricas para comprender la nueva experiencia de la humanidad. También en 1969, se puede encontrar este mismo sintagma nominal en las notas dedicadas a la misión del Apolo 11 a la Luna:

(36) Se superaron momentos de verdadera angustia en la investigación como lo fueron las caminatas en el vacío cósmico, las citas y acoplamientos de los navíos siderales ("El hombre hacia la Luna", $3^{a}$ sección dedicada al Apolo 11, LN, 16/7/1969, p. 1).

Estos últimos ejemplos pueden relacionarse con formas encontradas antes del período de interés. En el texto de 1928, al que aludíamos antes, se registran otras expresiones que muestran que los vehículos espaciales siempre se comprendieron por referencia al campo de la navegación marítima, entre ellas navio interplanetario y navio cohete.

Por razones de espacio no nos referiremos a la descripción de las estructuras, pero cabe destacar que se diferencia entre las partes que

292


corresponden al cohete propulsor y a la cápsula. Por otra parte, la forma de los vehículos habitables no era ahusada -como en los buques, dirigibles y aviones más modernos- ya que debían desempeñarse en el vacío de espacio y reingresaban a la atmósfera "cayendo" y no "volando". Sólo aparecen algunas voces como proa y popa. En cuanto a la instrumentación, podemos encontrar algunas denominaciones de la aviación, pero esto excede el objetivo del presente trabajo.

d. Para el caso de las maniobras, el medio espacial supone una novedad tan importante que, hasta el momento, no hemos identificado expresiones de la náutica sino otras como lanzamiento, acoplamiento, órbita, y sus correspondientes verbos.

e. La analogía entre las personas que tripulan los vehículos espaciales y los navegantes, marítimos y luego aéreos, también precede a la existencia real de estos tripulantes. En el texto de 1928, ya citado, la voz astronauta aparece en varias ocasiones: "La flota de los astronautas", "¿Qué sorpresas reservará [sic] a los astronautas la Luna y las otras tierras del cielo?", etc., y entre las fuentes del período 1957-1969, astronauta se encuentra testimoniada, como pudimos ver en el ejemplo 29, con anticipación a los primeros vuelos espaciales tripulados. ${ }^{22}$ En este sentido, cabe destacar que el primer grupo de astronautas ('persona que tripula una astronave o que está entrenada para este trabajo' [DRAE]) se conforma recién en el año 1959. ${ }^{23}$ Esta palabra aparece en todo el período, pero citamos este nuevo ejemplo que evidencia su rol de navegantes:

(37) El programa norteamericano Apolo, destinado a enviar astronautas a la Luna, confirma lo que ya se había establecido gradualmente en los vuelos espaciales anteriores: que esta es una época de navegantes espaciales y que los cuerpos celestes que se hallaban a distancias imposibles para el hombre están ahora a nuestro alcance ("Cronología de la gran aventura", LN, 16/7/1969, Sección 3 dedicada al Apolo 11, p. 2, descripción de fotografía).

Por otra parte, también se registra cosmonauta en los textos referidos, sobre todo, a las tripulaciones soviéticas, oposición que, desdibujada en algunos ejemplos, aparece con claridad en el siguiente fragmento:

22 Además, en el ejemplo 20 astronauta tiene un significado levemente diferente, incluyendo a toda persona interesada en la disciplina astronáutica.

23 Dickson (2009) indica que la forma inglesa, posteriormente seleccionada por la NASA, para referirse a los miembros de sus tripulaciones espaciales, apareció por primera vez en la novela de ciencia ficción de 1880 Across the Zodiac, por el autor Percy Greg. 
Expresiones de origen náutico en el nacimiento de las distintas formas de volar: aerostación, aviación y astronáutica / Lorena de-Matteis

(38) Comentarios editoriales transmitidos desde La Habana expresan: "Los Estados Unidos describen a Shepard como "astronauta", queriendo equiparar su vuelo parabólico con el viaje del "cosmonauta" Gagarin alrededor del mundo. Shepard pasó solamente un minuto en el espacio. Se le debe llamar más bien "nubenauta" "Todo se hizo conocer por radio y TV”, LN, 7/5/1961, p.1).

Estas voces muestran también los prefijos caracterizadores de muchos de los términos científicos, adoptados en la comunidad en relación con este ámbito: \{astro-\} y \{cosmo-\}. Tanto en el caso de astronauta como de cosmonauta, la permanencia de la raíz \{nauta\} retoma el histórico vínculo entre las distintas posibilidades de navegación. Aunque nos encontramos con unidades léxicas de origen técnico, al trasladarse a los discursos sociales sobre la astronáutica, entre ellos el periodístico, las relaciones analógicas que les dieron origen en la ciencia son explotadas en un nivel más profundo. De esta manera explican creaciones metafóricas ocasionales en los medios de la época, como nubenauta, o navío sideral que, entre otras, evidencian una concepción general de esta nueva modalidad del transporte de naturaleza metafórica, por referencia siempre al campo de la náutica.

\section{Conclusiones}

El análisis del uso cotidiano de términos de la náutica en la aviación y la astronáutica, pone en evidencia la importancia del orden metafórico en la conformación de los vocabularios cotidianos para las distintas modalidades del vuelo humano, que se perfeccionan y desarrollan a lo largo del siglo XX. Si bien algunas expresiones cayeron en desuso, una vez superada la necesidad cognitiva de aprehender las nuevas realidades, o bien han visto restringido su empleo a registros de tipo poético o textos históricos desapareciendo de los usos cotidianos (navío sideral, buque aéreo, navegante aéreo), el estudio de este vocabulario muestra una continuidad conceptual en los imaginarios sociales sobre estas modalidades del transporte, a partir de una analogía básica, como es la de pensar a los distintos espacios como nuevos océanos y a las distintas modalidades del transporte como formas diferentes de navegación, hecho que queda evidenciado en el nivel léxico-semántico.

Por otro lado, el análisis muestra que el orden metafórico de la náutica se manifiesta a través de expresiones de distinto tipo: a) unidades léxicas que son términos de trasvase y que, banalizadas, se adjetivan en el uso cotidiano para precisar su campo de referencia (nave aérea, navio

$+294$


sideral, navegante aéreo, etc.); b) unidades léxicas que son términos de trasvase generalizados en el uso cotidiano y que aparecen de manera independiente (nave, quilla, timón, proa, aeronauta, cosmonave, poner en franquía, etc.); y c) metáforas vinculadas a la náutica (nubenauta, navegar en el espacio, mar de nubes, piélago, corriente aérea). Enumeradas en orden de creciente cercanía con la expresión metafórica pura, aquella que omite el recurso de la comparación, todos estos tipos de expresiones remiten a una concepción analógica del vuelo humano como modalidad de la navegación. En una concepción tradicional de la metáfora como recurso característico del género literario -a la que, como queda claro, no adscribimos en este trabajo-, podría pensarse que, en el primer y segundo grupo, las expresiones corresponderían a un orden periférico de la metáfora. Pero si admitimos el orden metafórico como mecanismo de comprensión del mundo, este orden afecta también al ámbito de las terminologías y, como se ha mencionado, tanto los procesos de terminologización como de trasvase entre terminologías de distintas ciencias, se ven afectados también por procesos cuyo rasgo central es la analogía.

Para finalizar, la concepción de las distintas modalidades del vuelo humano, evidenciada en las expresiones analizadas, ha perdurado en el tiempo y, en este sentido, podemos sostener que el imaginario social sobre el vuelo humano (en cualquiera de sus formas) sigue debiéndole mucho al de la navegación marítima milenaria. Así lo demuestra el hecho de que algunas de las expresiones registradas, como navegación aérea, aeronave -empleada para todo tipo de vehículo aéreo- y aeronavegante -que reemplaza en el uso actual a navegante aéreo- continúen en vigencia en la comunidad bonaerense (y en otras de habla hispana), junto con otras que no hemos considerado en este trabajo como aeropuerto, puerta de embarque, embarcar, etc.

\section{Bibliografía}

Alarcón Hernández, P. (2004). "La escena básica de sembrar en tres metáforas conceptuales". Revista de Lingüistica Teórica y Aplicada 42(2), 45-66.

Álvarez de Miranda, P. (2008). "El léxico español, desde el siglo XVIII hasta hoy", en Cano Aguilar, R. (ed.) Historia de la lengua española. Barcelona: Ariel, pp. 1037-1064.

Baczko, B. (1991). Los imaginarios sociales. Memorias y esperanzas colectivas. Buenos Aires: Nueva Visión. 
Expresiones de origen náutico en el nacimiento de las distintas formas de volar: aerostación, aviación y astronáutica / Lorena de-Matteis

Barceló, J. (1980-1981). 'La función cognoscitiva de la metáfora en la retórica antigua'. Boletín de Filología XXXI, 97-110.

Barei, S. y E. del C. Pérez (comps.) (2006). El orden de la cultura y las formas de la metáfora. Córdoba: Facultad de Lenguas/ Universidad Nacional de Córdoba.

Cabré, M. T. (1999) La terminología: representación y comunicación. Elementos para una teoría de base comunicativa y otros artículos. Barcelona: Institut Universitari de Lingüística Aplicada/Universitat Pompeu Fabra.

Calsamiglia Blancafort, H. y Tusón Valls, A. (2002). Las cosas del decir. Manual de análisis del discurso. Barcelona: Ariel.

Conde Silvestre, J.C. (2007). Sociolingüistica histórica. Madrid: Gredos.

de-Matteis, L. M. A. (2005). 'Entre "Zeppelines” y "Boeings 747”: metáforas del vuelo y de la aviación en el habla cotidiana en español bonaerense'. Literatura y Lingüística 16, 221245.

(2007). "Los nidos de las aves mecánicas: algunas voces de la aeronáutica en español bonaerense en el período 1890-1914 y su importancia para la conformación de estereotipos", VIII Congreso Nacional de Hispanistas "Unidad y multiplicidad: tramas del hispanismo actual". Mendoza: Univ. Nacional de Cuyo, Tomo III, pp. 455-467.

(2009a). Aviación e Interacción Institucional. Análisis lingüístico de la interacción institucional aeronáutica en español en la Argentina. Bahía Blanca: EdiUNS.

(2009b). "Los nidos de las aves mecánicas II: algunas voces de la aeronáutica en español bonaerense en el período 1890-1914", en Killman, M. (comp.), La investigación en ciencias humanas y el rol de la educación en la transferencia. Actas de las III Jornadas de Jóvenes Investigadores en Ciencias Humanas. Bahía Blanca: Fundación Ezequiel Martínez Estrada, pp. 51-64.

(2010a). Apuntes léxicos para la historia aeronáutica y espacial: influencias, variación y perduración en el vocabulario español de la prensa escrita en Argentina (1900-1914 y 1958-1969). Monografía presentada al II Concurso de Monografías Inéditas de Historia Aeronáutica 
y Espacial, Secretaría de Cultura-Presidencia de la Nación e Instituto Nacional Newberiano. Inédita.

(2010b) "Navegación aérea y progreso: los textos de humor en el contexto del Centenario", en Aranda Durañona, O. (ed.), Centenario del vuelo mecánico 1919-2010. Actas del I Congreso de Historia Aeronáutica Argentina. Buenos Aires: Dirección de Estudios Históricos, Fuerza Aérea Argentina, pp. 197-215.

(en prensa). "Metáforas náuticas en los inicios de la aerostación y la aviación bonaerenses (1898-1914)", en Rigatuso, E. M. (coord.). Actas del I Congreso Internacional de Sociolingüística y Lingüística Histórica. Bahía Blanca: EdiUNS.

Dickson, P. (2009). A Dictionary of the Space Age. Baltimore: John Hopkins University Press.

Guilbert, L. (1965). La formation du vocabulaire de l'aviation. Paris: Larousse.

Hock, H. (1986). Principles of historical linguistics. Berlin: Mouton de Gruyter.

Lakoff, G. \& Johnson, M. (1998). Metáforas de la vida cotidiana. Madrid: Cátedra.

Lapesa, R. (1994 [1996]). "La lengua”, en El español moderno y contemporáneo. Estudios lingüísticos. Barcelona: Crítica, pp. 343-396.

Lüdtke, H. (1974). Historia del léxico románico. Madrid: Gredos.

Martín Camacho, José Carlos (2004). El vocabulario del discurso tecnocientífico. Madrid: Arco/Libros.

Mottura, L. (2006). "Retórica y vida cotidiana", en Barei, S. y E. del C. Pérez (comps.) p. 35-47.

Newton, W. P. (1965). "International aviation rivalry in Latin America 1919-1927", Journal of Inter-American Studies 7(3), 345-356.

Rojas, E. (1994). "Acerca de algunas metáforas de la oralidad argentina", BAAL LXI, 197-207.

Rothbart, D. (1984). "The semantics of metaphor and the structure of science", Philosophy of Science 51(4), 595-615.

Sanmartín Sáez, J. (2000). "La creación léxica (I). Neologismos semánticos: 
Expresiones de origen náutico en el nacimiento de las distintas formas de volar: aerostación, aviación y astronáutica / Lorena de-Matteis

las metáforas de cada día”, en Briz, A. ¿Cómo se comenta un texto coloquial? Barcelona: Ariel, pp. 125-142.

Schiffrin, D., Tannen, D. y Hamilton, H. (eds.) (2001). The handbook of discourse analysis. Oxford: Blackwell.

Viljanen, K. (2007). Wing, aile, Flügel. The origins and development of central aeronautical terms in some languages, Turku, online: http://personal.inet.fi/private/keijo.viljanen/ KOKOTYO.pdf

Vivanco Cervero, V. (2003). Homonimia y polisemia: teoría semántica y aplicación lexicográfica. Buenos Aires: Ediciones del Sur.

(2006). El español de la ciencia y la tecnología. Madrid: Arco/ Libros.

Wodak, R. y M. Meyer (2001). Methods of critical discourse analysis. Londres: Sage.

\section{Fuentes documentales}

Revista Caras y Caretas, colección completa. Buenos Aires, 1898-1914.

Diario La Nación, Buenos Aires, ejemplares varios entre 1957 y 1969.

Turner, C. (c.1918). La aviación al día. Barcelona: Sociedad General de Publicaciones. (Traducción de José Ma. Borras). 